Citation: Sadak, M. (2021). How do pre-service mathematics teachers enhance their lessons through lesson study?. International Journal of Scholars in Education, 4(1). 15-25. doi:10.52134/ueader.896081

\title{
How Do Pre-service Mathematics Teachers Enhance Their Lessons through Lesson Study?
}

\begin{abstract}
Musa SADAK*
Abstract: This study aimed to investigate how lesson study perspective could help pre-service teachers (PSTs) to enhance their mathematical instruction. Four PSTs along with their 13 other peers who took a semester long secondary level mathematics teaching methods course in one of the large-midwestern universities in the US participated in this study. While four PSTs planned and taught a lesson in two different groups by two, other PSTs took the role of giving feedback to their classmates. PSTs enhanced their lesson plans based on the feedback from their peers and provided self-reflections on these changes. As a result of the investigation of the changes PSTs did on their lesson plans and the reflections they provided, it was revealed that they enhanced their instruction on some specific issues, such as getting students' attention, using time efficiently, maintaining student interaction, using technology. It is also suggested to future researchers that it would be beneficial to study on PSTs' assumptions on the difference between the real students and the PSTs who pretended as students during the peer-taught lesson study activity.
\end{abstract}

Keywords: Lesson study, mathematics education, pre-service teachers, teacher education. 


\section{Introduction}

Despite the high availability of research on PSTs' knowledge development and the obstacles they encounter when starting the teaching practices, there was a limited direct research on their learning of teaching skills as a part of their teacher education focused undergraduate courses (Chen, Housner, \& Wayda, 2011, Incikabi \& Kacar, 2017; Pektas, 2014). That learners get involved in the learning, instead of only getting information from the instructor, has been determined as an essence of the education (Rubin, \& Hebert, 2010). If the aim is to improve teaching, practitioners should be supported to show their art with the intent to improve their practices. Their strategy could be engaging in teaching to cover what is needed, consequently the improvement will occur by gaining insight by the other people's help. And if the main focus is on reflection, teachers would think about what happened, why it happened, and what improvements they could actualize to reach desired goals (Cruickshank, \& Applegate, 1981). Collaborative learning and peer teaching are the encouraging learning methods among the active learning methods (Rubin, \& Hebert, 2010). Wilson and Berne (1999) indicated three circumstances of teacher learning in any professional development as sustainable learning environments: (i) learners' community that redefines the teaching practices, (ii) the environment that is designed to help teachers to activate and redefine their own professional development, and (iii) the environment that provides the opportunity for teachers to support and critique the works of each other.

Copland (2009) stated that feedback from pre-service teachers' (PSTs') peers has an impact of having tension on themselves since they felt having to act in the shoes of those feedbacks. However, the evaluations on PSTs' teaching performances given by their peers are more complimentary than the ones given by the students (Stronck, 1976). The sociocultural reflection perspective suggests that teachers more imperviously learn in the settings, in which they engage in shared dialogues, than individual contexts, and examining how they engage in these dialogues and form their learning are substantial to develop effective teacher learning communities, especially when they newly begin teaching practices (Guarino, Santibañez, \& Daley, 2006). Teachers will confidentially generate more specific and self-reliant actions to explain and change their practices if they take a part in a group where people are supported to dignify each other's thinking in a way that is reflective, growth-focused, and practice-based (Danielowich, 2012).

One example of peer evaluation-based team lessons was conducted by Burton (2005). In this research study, each student submitted their peer evaluation on team lessons that their peers taught as a requirement of a Methods and Materials of Teaching Mathematics in the Middle Grades class, and it was examined if these PSTs have fully included the six teaching standards of teaching mathematics of NCTM 1991. When teachers provide feedback to their colleagues, it enables their colleagues' and own learning at the same time (Danielowich, 2012).

Students' self- and peer-evaluations have essential learning outcomes for the students, additionally to the benefit of decreasing the teacher's work (Ozogul, Olina, \& Sullivan, 2008). Danielowich (2012) also indicated as a result of his study that teachers' individual learning could be more supported with the following two conditions: when their own contradictions about their teaching are clear prior to their performance, and when they participate in the peer dialogues to reconsider their teaching adoptions and enhance their critical thinking.

In their study on teacher-, self-, and peer-evaluation groups, Ozogul et al. (2008) indicated that all the students in these three evaluation groups considerably enhanced their performances from draft to the revised lesson plans. They also stated that peer-evaluators gave more feedback than the self- and teacher-evaluators. From the metacognitive perspective, when students formally involved in evaluating their works, they could determine the mastery level 
that they had, and realize the shortcomings of their work. While self-evaluation allocates students to be in an active role in critically thinking on their skills and own learning, peerevaluation provides students to engage these processes in both way: as an evaluator, and the person being evaluated. Consequently, when students are having the both role of evaluators of and being evaluated by their peers, it affects the type and importance of the feedback that they give (Ozogul et al., 2008).

During the peer-evaluation process, getting feedback on their teaching from their peers provides opportunity for students to metacognitively aware of their self-evaluation skills by comparing to their peers' work (Topping, Smith, Swanson, \& Elliot, 2000). Additionally, peerevaluation allocates students to well understanding of the rubric through which they provide feedback, and to reduce the mistakes on their lesson plans (Ozogul et al., 2008).

\section{Theoretical Model of the Lesson Study}

Japanese Lesson Study became popular with the release of TIMSS 1999 Video Study especially in the Western and South-Eastern countries (Stigler, Gonzalez, Kawanaka, Knoll, \& Serrano, 1999). Doig and Groves (2011) claimed that Japanese Lesson Study offers a model of extensive and maintainable professional development opportunities. Lewis, Perry and Hurd (2009) provided a theoretical model for the Japanese Lesson Study that was drawn from the researches made at the center of these studies. Based on this model, there are four features of a lesson study: Investigation, Planning, Research Lesson and Reflection. What should be included in these features when conducted a lesson study is illustrated in detail in the following table (Table 1).

Table 1.

Theoretical Model of the Lesson Study

\begin{tabular}{ll}
\hline \multirow{3}{*}{ Investigation } & $\begin{array}{l}\text { a. Consider students' current characteristics } \\
\text { b. Consider long term goals for student learning and development } \\
\text { c. Study the content area: key concepts, existing curricula, standards, } \\
\text { learning trajectory, research }\end{array}$ \\
\hline \multirow{3}{*}{ Planning } & $\begin{array}{l}\text { a. Select or develop research lesson } \\
\text { b. Try task in order to anticipate student solutions } \\
\text { c. Write up instructional plan, including goals for student learning and } \\
\text { development, anticipated student thinking, data collection points, } \\
\text { rationale for lesson design, connection to long-term goals }\end{array}$ \\
\hline Research Lesson & $\begin{array}{l}\text { a. Conduct research lesson } \\
\text { b. Team members observe and collect data during live research lesson }\end{array}$ \\
\hline \multirow{5}{*}{ Reflection } & $\begin{array}{l}\text { a. Share and discuss data from research lesson in post-lesson colloquium } \\
\text { b. Team members (and often other observers) draw out implications for }\end{array}$ \\
& $\begin{array}{l}\text { lesson redesign, for teaching-learning more broadly, and for } \\
\text { understanding of students and subject matter }\end{array}$ \\
c. Summarize in writing what was learned from cycle, to consolidate the \\
learning \\
d. [Revise and reteach the lesson]*
\end{tabular}

*An optional feature (Lewis et al., 2009, p. 287)

For this study, these crucial four elements of the lesson study were integrated into PSTs' implementation of the lesson. Table 2 illustrates how these four elements were included in the rubric of their lesson plans. Objectives they needed to provide in their lesson plans were reflected as sub-headings in the construct of the implementation of the lesson study with connection to each element. 
Table 2.

The Linkage between the Theoretical Model and the Implementation of the Lesson Study

\begin{tabular}{ll}
\hline Theoretical Model & Implementation of the Lesson Study \\
\hline & - Determination of Title of the lesson \\
& - Determination of Target audience of the lesson \\
& - Determination of Overall goal of the lesson \\
& - Determination of Common Core State Standards and Mathematical \\
& Practices Addressed \\
& - Determination of Student learning objectives \\
& - Determination of Student prior knowledge \\
& - Determination of Assessment \\
& - Determination of Length of the lesson \\
& - Scheduling the Activities \\
& - Determination of Adaptations \\
& - Determination of Materials needed \\
Planning & - Implementation of the planned lesson in the classroom - 45 minutes \\
& - Observation by the group members and other PSTs \\
\hline Research Lesson & - Feedback from the peers in the classroom - 30 minutes \\
& - Revising lesson plan based on the feedback \\
Reflection & - Writing overall reflections on the revisions \\
\hline Lewis et al. (2009, p. 287)
\end{tabular}

\section{Methods}

\section{Study Design}

Four PSTs who are taking semester-long secondary level mathematics teaching methods course in one of the large mid-western universities in the US participated in this study along with their 13 other peers who are the ones giving feedback to these four students. These four PSTs were consisted of two groups by two. While a group of two students were teaching a lesson other 15 PSTs were in the role of giving feedback. They taught a lesson on two topics of geometry $(\mathrm{G})$ and mathematical applications (M) with a group of two (one group consists two) to their classmates for the first 45 minutes of a class session, and got feedback from them for the last 30 minutes, where one class session was 75 minutes. Students were also required to have a meeting with the instructor of the course to discuss their teaching ideas at least one week prior to their class teaching, and then planned the lesson. After teaching the lesson in the classroom and getting feedback from their peers, PSTs revised the lesson based on the feedback, and actually redesigned the lesson plan with the changes.

For the peer-taught lesson study, they planned the lesson as a group based on the following three phases: Before, during, and after, as explained above. When they submitted their group lesson plans on these three phases before they teaching the lesson, they used the following blank form (Figure 1). The inclusion of the elements of this template was already given in Table 2.

\begin{tabular}{|l|}
\hline Title of the Lesson: \\
\hline Audience of the Lesson: \\
\hline Aim of the Lesson: \\
\hline Student Learning Objectives: \\
\hline Student Prior Knowledge: \\
\hline
\end{tabular}


Assessment: (Go back to "student learning objectives". What will your audience do to show that they fulfil the "student learning objectives?" Please make sure each student learning objective is matched up with an assessment objective)

Common Core State Standards (CCSS) and Mathematical Practices: (Download, copy and paste the CCSS standard from the website: http://www.doe.in.gov/standards/mathematics)

Length of Lesson:

45 minutes (one day)

Activities Schedule: (Specifically think about what students and teachers will do in each step) Launch/Before: (minutes)

Investigate/During: (minutes)

Summarize/After: (minutes)

Adaptations: (How can you control to gear up or gear down the lesson based on your initial observation? How can you accommodate students with special needs?)

Materials Needed: (Think about the activities you planned and consider the materials and technologies needed in your lesson)

Figure 1. Lesson Plan Template for Peer-taught Lesson Activity

"Before, during and after" (BDA) model is a lesson structure format, through which activities of the lesson could be organized in a way that students could catch the principal meanings that lie under the lesson (Wilburne, \& Peterson, 2007). They indicated that if, especially mathematics, classes were designed by the activities based on BDA model, it would allocate effective teaching and learning environment, and improve students' mathematical experiences.

In the "before" phase, teacher gets students' attention to the lesson, and sets up the platform of the main content. The activities in the before phase could be in a format of prompt review of the prior lessons to revealing students' prior knowledge, or be a quick review of common mistakes related to the main topic, and also could be a quick assessment of skills needed in the "during" phase. In the "during" phase, the core content of the lesson is provided to the students, and students involve in the experiments, investigations, and concept discoveries as in the small groups or individuals. Finally, "after" phase mainly relies on a reflection practices on what explored in the "during" phase, and it provides students to make sense of the mathematical concept covered in the lesson, and the further extensions on reasoning and problem solving skills (Wilburne, \& Peterson, 2007).

Following Table 3 is the guiding questions formed by Wilburne and Peterson (2007) to help teachers to facilitate before, during, and after phases in their lesson plans. Students in this activity examined this table when learning peer-taught lesson activity.

Table 3.

Teachers' Guide to Developing a Before-During-After Lesson

- Does it relate to today's lesson?

- Is it a 5- to 10-minute activity?

The Before Phase - Does it grab students' attention?

- Does it allow for connections and/or assess prior knowledge?

- Do students have the opportunity to share their thinking?

- Does it actively engage students?

- Is it aligned with academic standards?

- Does it meet the course/content objectives?

The During Phase

- Does it reflect a problem-solving approach?

- Does it promote opportunities for students to communicate their learning? 


\begin{tabular}{lll}
\hline & - Are students actively talking, reading, writing, and making sense \\
& of the mathematics? \\
\hline The After Phase & Does it require application of the new knowledge? \\
& - Does it assess what the students have learned? \\
& Does it provide opportunity for the students to reflect on their \\
& learning and make sense of the mathematics?
\end{tabular}

(Wilburne and Peterson, 2007)

Based on lesson template plan and BDA activity, which is also included in the lesson template plan, PSTs prepared the lesson. Afterwards, they taught the lesson to their peers. At the end of each group's teaching, other PSTs who were in the student position gave feedback (verbally and in a written format) to their classmates also based on these three phases. After PSTs, who taught the course, took notes what their classmates pointed about their teaching and collected the written feedbacks, they submitted the individual revised lesson plans also on this form, but with the changes at this time and not as a group. Additionally to the revised lesson plans, PSTs were also required to submit their individual self-reflections on the lesson they taught.

\section{Data Collection and Analysis}

For this study, students' lesson plan submissions on the form (Figure 1), both the prior group lesson plan and revised individual one, and their individual self reflections on the lesson plans were used as a data source to define the changes. Those two lesson plans could be defined as a pre- and post-data determining the changes that PSTs did through the help of peer-taught lesson study, and the self-reflections could be defined as an explanatory for the changes. Thus, with these two plans PSTs submitted, it was analyzed what PSTs still want to include, or want to eliminate from the previous plan, and was narratively reported in the discussion part. And, their self-reflections revealt the reasons of why they wanted to change or keep the same the lesson plans. Some excerpts from the lesson plans are also provided in the discussion section to give the sense of the changes that PSTs did. Between the pre- and post-lesson plans, it was employed a simply thematic content comparison to uncover the changes that was caused by the peer-taught lesson study, and reach the main bullets of changes.

\section{Discussion}

\section{Group 1: Geometry (G)}

In the geometry group, two students (G1, and G2) provided post- lesson plans with the changes that they made on the pre- lesson plan on the "lesson plan template" (Figure 1) format. Figure 2 is provided as their pre- lesson plan that they submitted as a group. Since they only changed the "schedule of activities" part in their individual post-lesson plans from pre- lesson plan, Figure 2 only shows that part to make sense of the changes they did. The remained parts of the lesson plan were the same on both pre- and post- lesson plans by these two students. Therefore, those parts were not included.

\begin{tabular}{l} 
Activities Schedule: (Specifically think about what students and teachers will do in each \\
step) \\
\hline Launch/Before: $(\mathbf{5}$ minutes) \\
Teachers: Question about what are parallel lines (i.e. what does it mean if two lines are \\
parallel, what does that look like) and what is a transversal \\
Students: Create a set of parallel lines and transversal in GSP while teachers walk around and \\
check what they are doing
\end{tabular}




\section{Investigate/During: (25 minutes)}

Students: Work on GSP worksheet on exploring parallel lines and angles

Teachers: Walk around room and provide support

\section{Summarize/After: (10 minutes)}

Students: Share out discoveries from completing worksheet exploration

Teachers: Guide discussion

Figure 2. Pre- lesson design of the geometry group (G1 and G2)

Based on their first lesson plan (Figure 2) G1 made a change in the "before" phase by adding the time separation for teacher's and students' to do statements, at first (Figure 3). Then added 4 warming up questions to the teacher's 5 minutes part. G1 stated on her self-reflection, which might be the clue on the change she did:

\footnotetext{
The warm up was a little short. I think for a group of college students who know all of this forward and backward, it was fine, but teaching this to actual high school students would require more to be done and probably something more engaging.
}

The other change G1 did on the pre- lesson plan was on the "after" phase by making a specific explanation on teacher's part (Figure 3). The further explanation was about the homework assignment for the following lesson, and teacher's guidance about it if the class time lets to do so. She stated about this change on her self-reflection:

The homework assignment could have been structured a little better, but part of that was me having the spur of the moment idea of each of them to write their own definition rather than allowing one or two people in the class to do all of the thinking and answering the question for everyone else.

\begin{tabular}{|c|}
\hline $\begin{array}{l}\text { Activities Schedule: (Specifically think about what students and teachers will do in each } \\
\text { step) }\end{array}$ \\
\hline Launch/Before: (15 minutes) \\
\hline $\begin{array}{l}\text { Teachers: Question about what are parallel lines (i.e. what does it mean if two lines are } \\
\text { parallel, what does that look like) and what is a transversal ( } 5 \text { minutes) }\end{array}$ \\
\hline Question 1: What does it mean when two lines are parallel? \\
\hline - Question 2: What is a transversal line? \\
\hline $\begin{array}{l}\text { Question 3: How many angles are formed from two parallel lines and their } \\
\text { transversal? }\end{array}$ \\
\hline $\begin{array}{l}\text { - Question 4: Can a transversal line intersect non-parallel lines? Or is it specific to } \\
\text { parallel lines? }\end{array}$ \\
\hline $\begin{array}{l}\text { Students: Following along with teacher, create the GSP file that will be used in the } \\
\text { exploration ( } 10 \text { minutes })\end{array}$ \\
\hline Investigate/During: (20 minutes) \\
\hline Students: Work on GSP worksheet on exploring parallel lines and angles \\
\hline Teachers: Walk around room and provide support \\
\hline Summarize/After: (10 minutes) \\
\hline Students: Share out discoveries from completing worksheet exploration \\
\hline $\begin{array}{l}\text { Teachers: Guide discussion of discoveries, lead students to homework assignment of writing } \\
\text { a definition of parallel lines involving the angles, give time to work in class on assignment } \\
\text { with teacher around to help }\end{array}$ \\
\hline
\end{tabular}

Figure 3: Post- lesson design from the geometry group (Student G1). The changes that Student G1 did provided with blue-colored form

G1 also indicated separately from the lesson plan form:

Having this projected on technology may have been useful, so I was not constantly erasing the board between groups. 
On the other hand, G2 made an addition on the "during" phase, at first (Figure 4). As could be seen, G2 added an objective for the student to share their experience on Geometric Sketch Pad (GSP) with their classmates. Also, G2 added that teacher could initially help the students when they were lost in working on the GSP by illustrating an example on the board. She also indicated that when teachers walk around the class, they should work cooperatively with the students in the groups. In her self-reflection, G2 stated regarding this issue:

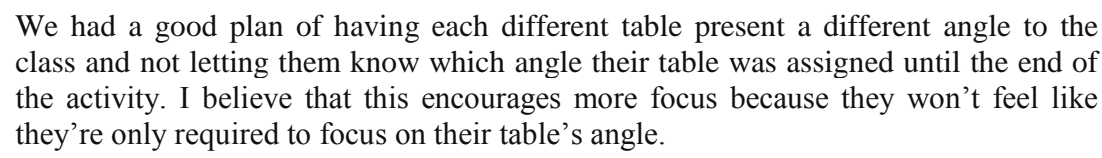

Lastly, G2 added also on the "after" phase in the student role that students could develop a definition for parallel lines by the help of different types of angles (Figure 4). In regard to this point she reported on her self-reflection:

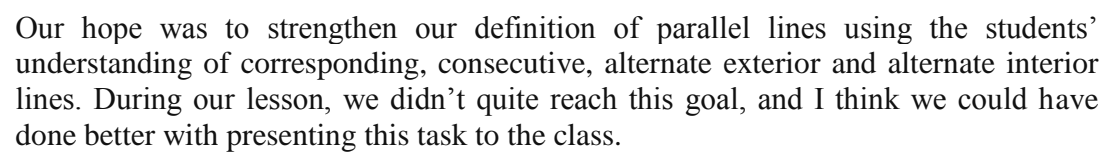
understanding of corresponding, consecutive, alternate exterior and alternate interior lines. During our lesson, we didn't quite reach this goal, and I think we could have done better with presenting this task to the class.

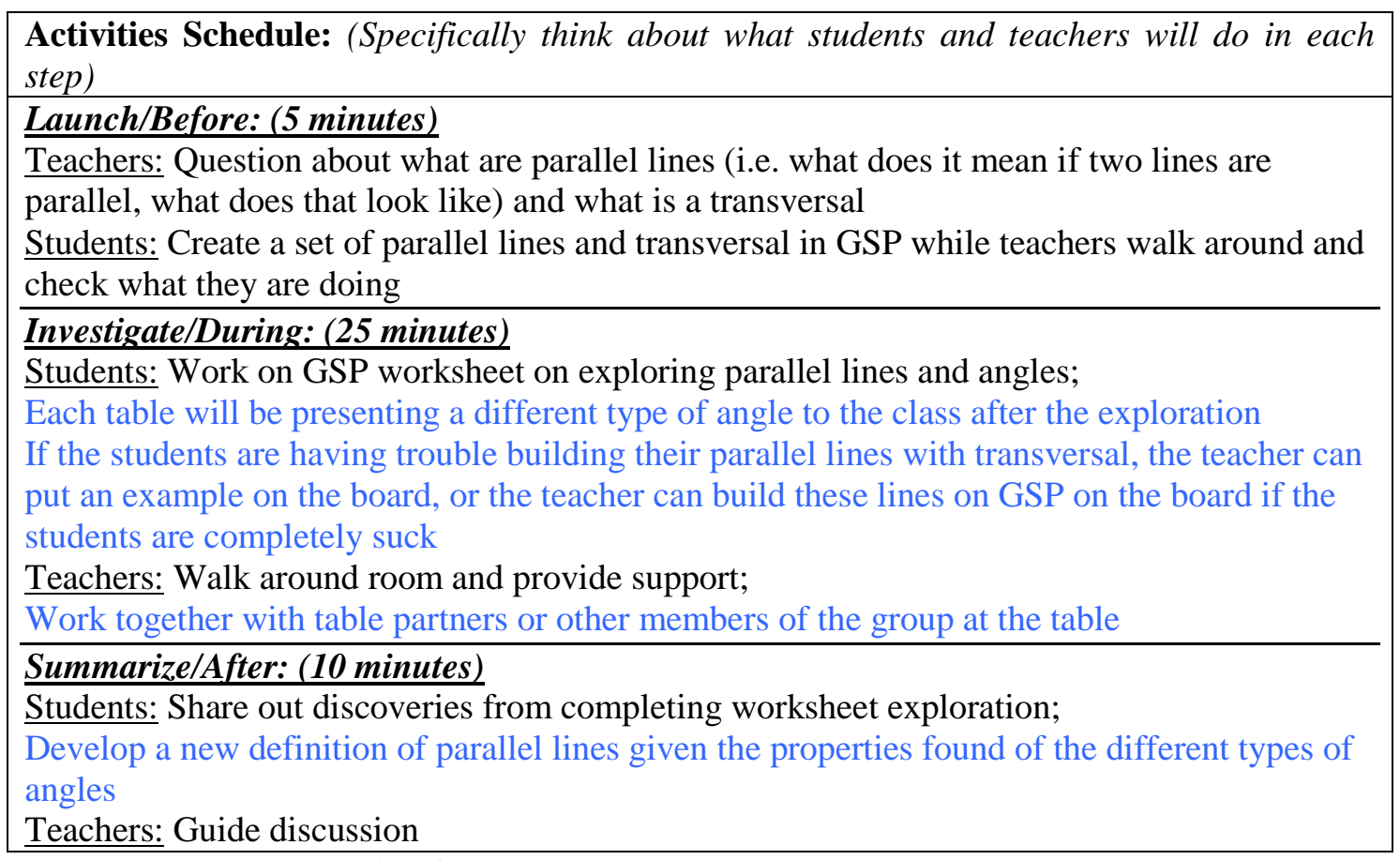

Figure 4: Post- lesson design from the geometry group (Student G2). The changes that Student G2 did provided with blue-colored form.

\section{Group 2: Mathematical Applications}

In the mathematical applications group, two students (M1, and M2) provided their preand post- lesson plans in addition to their self-reflections on the changes that they did between these plans. However, they did not follow the "lesson plan template" (Figure 1) to explain their work, and created their pre- and post- lesson plans on an essay based structure. Therefore, the analysis of the changes that they did is provided narratively. 
In their group pre- lesson plan, they planned to have 10 minutes "opener", 10 minutes "quadratic review", 20 minutes "battleship [an activity]", and 10 minutes closure activities. In the "opener" activity, they planned to ask some challenging questions about the real world applications of quadratics and parabolas, and then followed by a brief discussion video on parabolas in the real life. In the "quadratic review" activity, they designed a slide presentation on quadratic formula, quadratic form, aspects on graphing quadratic, and vertex and intercepts in the quadratics. They said this would be a good opportunity for students to ask questions to get answers in the following activity. In the "battleship" activity, students were supposed to work on a real life scenario to apply their knowledge by the use of technological graphing devices. Lastly, in the "closure" activity, they planned to have closure discussion with the whole class members on what they did during the prior activities.

In his individual post-lesson plan, M1 enhanced the "opener" activity with a "thinkpair-share" activity, through which students brainstorm alone and share with the group, and then with the whole class. He also changed the brief video in this activity. He explained why he did these changes in his self-reflection:

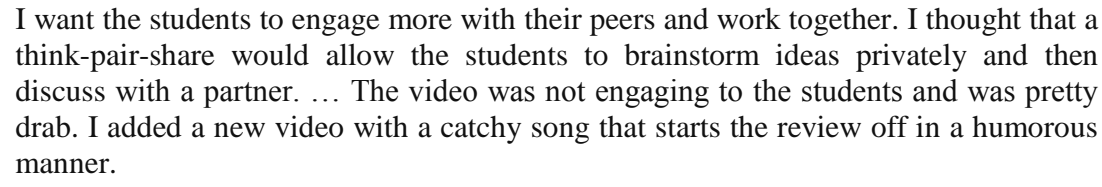

He, then, changed the time of the "quadratic review" activity to 5-7 minutes, and added an activity followed by the slide presentation that students have discussions about the problems given in the presentation. M1 also added on the "battleship" activity that students work at their own paces. For the students who finished the activity earlier, he suggested a battleship game based on firing on a missile by playing with quadratic equations. The clue on why he added some activities on the "quadratic review" in his self-reflection could be:

No one seemed particularly bored by the activity that we were doing and it seemed to be quite enjoyable.

However, M2 only changed the time allocated for the "opener" and "battleship" activities, from 10 to eight, and 10 to 32, relatively. It was the only addition he made on the prelesson plan. He also eliminated the "quadratic review" activity. He explained why he changed the time allocation for the activities and eliminated the "quadratic review" in his self-reflection:

\footnotetext{
The biggest problem with our lesson is that we did not leave enough time to wrap-up the activity and allow students to discuss their problems and solutions. ... If I could teach the lesson again, I would do one of three things to make sure we have enough time at the end of the lesson to discuss. First, I would remove the quick review that took place in the opening of the lesson after the video and move into the activity sooner.
}

\section{Conclusion and Implications}

Lesson studies are helpful in PSTs' growth in their instructional abilities (Doig \& Groves, 2011; Stigler et al., 1999). PSTs who engaged in the peer-taught lesson study gave some hints about the types of changes that they did based on the feedback they got from their classmates. This study revealed that when PSTs taught a lesson to their peers, they enhanced their teaching in various ways as previous researchers indicated (Cruickshank, \& Applegate, 1981; Rubin, \& Hebert, 2010; Stronck, 1976; Guarino et al., 2006; Danielowich, 2012). They did the changes by adding some new ideas, eliminating some activities, or even giving emphasize on some context that they already covered in their pre-lesson plans, and getting 
positive feedback from their classmates about it.

The most common issue that PSTs reported in their self-reflections and included in their post- lesson plans is "getting all students' attention in the classroom". Students G1, G2, and M1 made changes on their pre- lesson plans with the special focus on students' attention. Another important issue PSTs indicated is that the "time management" in the classroom. Students G1 and M2 reported this issue on their self-reflections and changed their pre- lesson plans based on this issue. The third important matter that PSTs struggled with is "maintaining students" interactions". The changes by students G2 and M1 indicated the importance of this.

PSTs stated other enhancements additionally to three cases, which were stated above, through this peer-taught lesson study that technology use in the classroom could be a better strategy to make the teacher's work easier (G1); teachers could be engage in the students' working groups actively (G2); and students' exploration could be useful with the support by some teachers' presentation (G2). Therefore, the PSTs' enhancements through the peer taught lesson were the following:

- Getting students' attention during the lesson,

- Using the lesson time efficiently,

- Maintaining students' interactions with each other,

- Using technology,

- Actively engaging students' work groups,

- Supporting students with direct presenting of the information when needed.

Additionally, one student mentioned that if the lesson she taught was with the real students, she could teach in different way. This case could be an example of a limitation of the peer-taught lesson. When PSTs present their teaching to their classmates as a real teaching practice, they confused with the audience level, and mixed the lesson based on the PSTs' and intended real students' level.

In conclusion, peer taught lesson study in this secondary level mathematics methods class environment enhanced PSTs' teaching abilities in the ways that described above. All students who provided their pre-, post- lesson plans, and their reflections made changes on their pre-lesson plans, and conducted their post-lesson plans with those changes. Their selfreflections helped us to understand why they changed the parts of the lessons. However, as one of the PSTs indicated, peer taught lesson study might not be effective for some PSTs since they may think the students in the real class environments would be totally different than the PSTs who pretended as students.

For the further studies, it would be really beneficial to study on PSTs' assumptions on the difference between the real students and the PSTs who pretended as students during the peer-taught lesson study activity. Since they teach their planned lessons to their classmates, instead of the real students who were in the intended level, PSTs' teaching approaches may be affected by this assumption during the peer-taught lesson study, and it is also possible that PSTs could not reveal their teaching strategies to enhance through this study. Thus, it would be helpful for researchers to find out the extent to which PSTs assume their classmates as real students whom they will teach in the future while they teach a lesson as a practice to their peers. 


\section{References}

Burton, K. S. (2005). Using student peer evaluations to evaluate team taught lessons. Journal of Instructional Psychology, 32(2), 136.

Chen, H., Housner, L., \& Wayda, V. (2011). The Development of Teaching Skills in Preservice Teachers. International Journal of Applied Sports Sciences, 23(2), 465-486.

Copland, F. (2010). Causes of tension in post-observation feedback in pre-service teacher training: An alternative view. Teaching and Teacher Education, 26(3), 466-472.

Cruickshank, D. R., \& Applegate, J. H. (1981). Reflective teaching as a strategy for teacher growth. Educational leadership, 38(7), 553-554.

Danielowich, R. M. (2012). Other teachers' teaching: Understanding the roles of peer group collaboration in teacher reflection and learning. The Teacher Educator, 47(2), 101-122.

Doig, B., \& Groves, S. (2011). Japanese lesson study: Teacher professional development through communities of inquiry. Mathematics teacher education and development, 13(1), 77-93.

Guarino, C. M., Santibañez, L., \& Daley, G. A. (2006). Teacher recruitment and retention: A review of the recent empirical literature. Review of educational research, 76(2), 173208.

Incikabi, L., \& Kacar, A. (2017). Analyzing Prospective Mathematics Teachers' Development of Teaching Practices in Mathematics: A Lesson Study Approach. In J Keengwe \& G. Onchwari (Eds.), Handbook of Research on Learner-Centered Pedagogy in Teacher Education and Professional Development (206-225). Hersley, PA: IGI Global.

Lewis, C. C., Perry, R. R., \& Hurd, J. (2009). Improving mathematics instruction through lesson study: A theoretical model and North American case. Journal of Mathematics Teacher Education, 12(4), 285-304.

Ozogul, G., Olina, Z., \& Sullivan, H. (2008). Teacher, self and peer evaluation of lesson plans written by preservice teachers. Educational Technology Research and Development, 56(2), 181-201.

Pektas, M. (2014). Effects of lesson study on science teacher candidates teaching efficacies. Educational Research and Reviews, 9(6), 164-172.

Rubin, L., \& Hebert, C. (1998). Model for active learning: Collaborative peer teaching. College Teaching, 46(1), 26-30.

Stigler, J. W., Gonzalez, P., Kawanaka, T., Knoll, S., \& Serrano, A. (1999). The TIMSS videotape classroom study: Methods and findings from an explanatory research Project on eighth-grade mathematics instruction in Germany, Japan and the United States (No. NCES 99-074). Washington, DC: US Government Printing Office.

Stronck, D. R. (1976). A comparison of peer and pupil evaluation of lessons taught by preservice biology teachers. Science Education, 60(2), 217-221.

Topping, K. J., Smith, E. F., Swanson, I., \& Elliot, A. (2000). Formative peer assessment of academic writing between postgraduate students. Assessment \& Evaluation in Higher Education, 25(2), 149-167.

Wilburne, J. M., \& Peterson, W. (2007). Using a Before-During-After (BDA) Model to Plan Effective Secondary Mathematics Lessons. Mathematics Teacher, 101(3), 209-213.

Wilson, S. M., \& Berne, J. (1999). Teacher learning and the acquisition of professional knowledge: An examination of research on contemporary professlonal development. Review of research in education, 24(1), 173-209. 